\title{
A Rare Case of Primary Upper Extremity Varicose Veins
}

\author{
Ramisertti Bhargavi² Tammiraju Iragavarapu ${ }^{1} \quad$ A Aswini Kumar ${ }^{2}$ \\ ${ }^{1}$ Department of Cardiology, ASRAM Medical College, Eluru, Andhra \\ Pradesh, India \\ 2Department of General Medicine, ASRAM Medical College, Eluru, \\ Address for correspondence Tammiraju Iragavarapu, MD, \\ DM, Department of Cardiology, ASRAM Medical College, Eluru, \\ Andhra Pradesh, India (e-mail: vmrtraju.mbbs@gmail.com).
} Andhra Pradesh, India

Ind J Car Dis Wom 2019;4:29-31

\begin{abstract}
The incidence of varicosities of upper extremity is far most uncommon from that of lower extremity varicose veins for varied reasons even though the causes are almost the same. Here, the authors present a case of right upper limb varicose veins in a 55 -year-old female who is a housewife. After ruling out all the secondary and congenital causes on clinical and Doppler study, the authors diagnosed it as a case of primary

Keywords

- upper limb

- varicosity

- primary upper extremity varicose veins. They referred the case to a vascular surgeon but the patient denied the surgery, and is lost to follow-up. Hence, the authors report this case of primary upper limb varicosities as the incidence is very low when compared with lower extremity, and not much of literature is available except for a few case reports.
\end{abstract}

\section{Introduction}

Varicose veins are uncommon in upper limbs when compared with lower limbs. ${ }^{1}$ However, the causes of varicose veins remains the same in both the extremities. Patients with lower limb varicosities are more prone to develop varicosities in upper limb as well. Patients who lift heavy weights, those with congenital disorders such as Klippel-Trenaunay syndrome, and those with arteriovenous fistulae for hemodialysis are more prone to upper limb varicosities. ${ }^{2}$ Treatment options available for upper limb varicose veins are more or less similar to those of lower limb varicosities, that is, ligation and stripping, sclerotherapy in selected cases. We report a rare case of primary varicose veins in the right arm and forearm in a 55-year-old female.

\section{Case Report}

A 55-year-old female presented with complaints of soft swellings over her right arm and forearm since 6 months, which were progressively increasing in size since that time. Swellings are not associated with pain. No previous history of trauma. No similar complaints in the past. No similar complaints in the family. On examination, there are multiple, soft, compressible, out-pouchings of $1.5 \times 1.5 \mathrm{~cm}$ on lateral aspect of the right forearm and arm along the cephalic vein distribution ( - Fig. 1). When the arm is elevated above the head, these swellings disappear (- Fig. 2). Surrounding skin appears to be normal. Bilateral pulses were normally felt. No bruit heard on auscultation. No discrepancy in arm sizes of both limbs. Left upper limb and bilateral lower limbs appear to be normal. The color and pulse wave Doppler study of venous system of the right upper limb shows incompetent valve at brachiocephalic junction. No findings suggestive of thrombosis, perforator incompetence. No arteriovenous shunts seen. Patient has been referred to a surgeon and the need for treatment was explained, but the patient denied the surgery and was lost to follow-up.

\section{Discussion}

A vein that becomes dilated, elongated, tortuous, and thickened due to continuous pressure is called as a varicose vein. ${ }^{3}$ Etiology of varicose veins can be categorized into congenital, primary, or secondary. In the primary type of varicose veins, there will not be underlying cause and may be due to floppy valve cusps, causing the incompetence in valves. ${ }^{4}$ Incompetent perforating veins is the commonest etiology for lower limb varicose veins. But in case of upper limbs, the valves within the perforating veins are directed toward the superficial veins, making this a less common cause for upper extremity varicose veins. ${ }^{5}$ Congenital anomalies that includes 


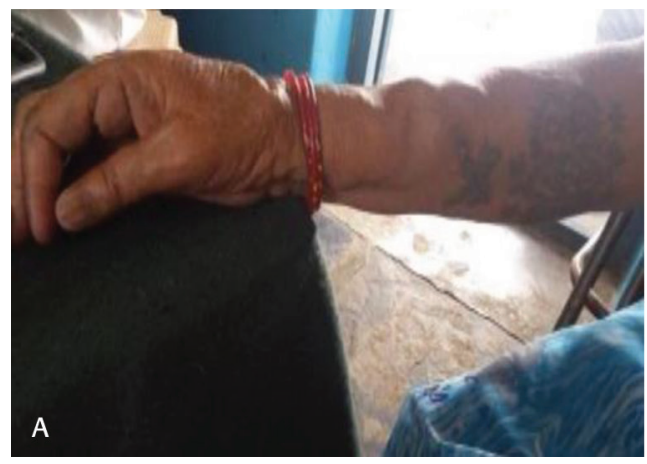

Fig. 1 Varicose veins of right upper limb in dependent position.

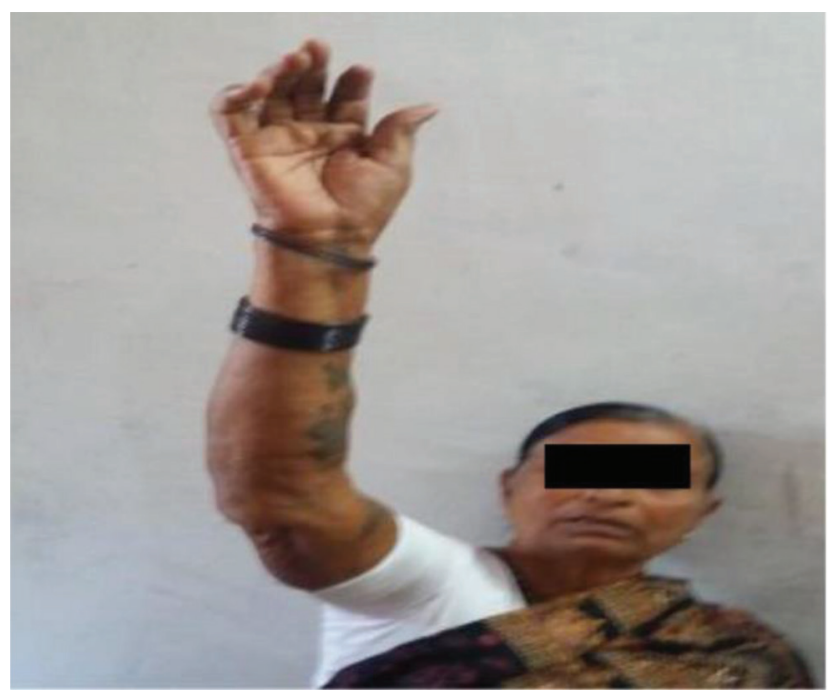

Fig. 2 Emptying of varicose veins on elevating the right upper limb.

Klippel-Trenaunay syndrome (soft-tissue hypertrophy, cutaneous hemangioma, varicose veins) and Parkes Weber syndrome (Klippel-Trenaunay syndrome triad and functional arteriovenous fistula) are rare. Congenital arteriovenous fistulas are associated with cutaneous hemangiomas and may be diffused or localized. ${ }^{6,7}$ In the secondary type of varicose veins, there will be underlying precipitating causes. Secondary varicose veins can be due to venous outflow obstruction as a result of deep vein thrombosis or arteriovenous fistulae. Arteriovenous fistulas created for hemodialysis leads to high venous blood pressure, leading to vein dilatation and chronic venous stasis within the limb. Furthermore, the subclavian vein obstruction can increase the venous pressure in patients having dialysis. Recurrent needle trauma can also lead to venous aneurysms. Varicose veins of the fingers are also stated, which can be due to repeated trauma. In comparison with varicose veins in the lower extremity, thin walled arm veins hardly ever become varicose.

\section{Varicose Veins Pathophysiology}

Valvular incompetence with axial reflux. Increased venous pressure leading to dilation, lengthening which causes further valve damage. It causes extravasation of fluid and proteins

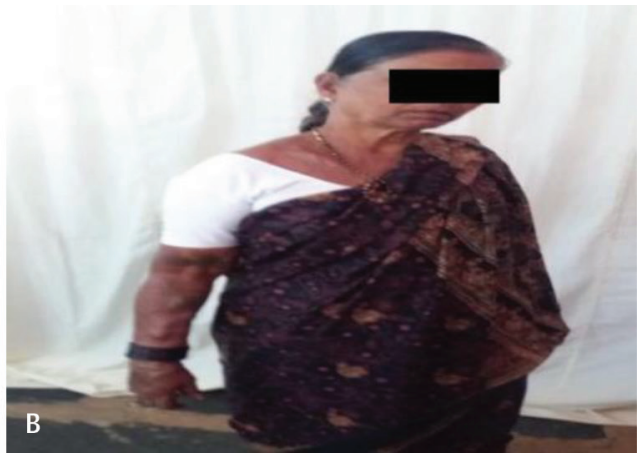

into the soft tissue. In the standing position, the elevated hydrostatic pressure that was transmitted to the lower limbs is a major factor in lower limb varicose veins, which is not the usual case in upper limbs. ${ }^{1}$ The varied presentation of varicose veins can range from simple venectasia to tortuous varicosities associated with dermatitis, ulcers, or severe discoloration.

\section{Diagnosis}

A good clinical history and examination plays a major role in identifying upper extremity varicose veins. Color flow Doppler ultrasound is necessary not only to diagnose but also to identify underlying etiology for varicose veins, which is a noninvasive investigation. With the availability of this noninvasive modality, more invasive methods are reserved for uncommon conditions such as congenital variants to further identify the pathology. ${ }^{2}$ Absence of cutaneous markers for congenital vascular anomalies can exclude congenital causes. We did not suggest computed tomography venography as Doppler examination itself revealed the diagnosis and ruled out any obstruction or fistula.

\section{Treatment}

The treatment options for upper limb varicosities and lower limb varicosities are almost the same. The routinely used stab avulsion technique in combination with stripping provides good cosmetic and functional results and has stood the test of time in case of varicosities of the arm or forearm. ${ }^{8}$ Besides ligation and stripping, multiple ligation and excision of localized varicose vein segments also provides excellent results in hand varicose veins. Compression sclerotherapy with agents such as sodium tetradecyl sulfate or polidocanol is an alternative to surgery for varicosities of the dorsum of hand. ${ }^{9}$ Laser ablation and endovenous therapy for localized varicosities are yet to be evaluated. The treatment for varicosities due to arteriovenous fistulae is generally surgical by ligation of distal venous limb of a side to side fistula or division of the fistula itself. ${ }^{4}$ Regardless of the treatment modality, recurrence rates are high. In our case, patient denied all treatment modalities available. The salient features of upper extremity varicose veins are presented in -Table $\mathbf{1}$. 
Table 1 Characteristic features of primary upper limb varicose veins

\begin{tabular}{|c|c|}
\hline \multicolumn{2}{|c|}{ Incidence of upper extremity varicose veins is very less. } \\
\hline Etiology & $\begin{array}{l}\text { - Primary } \\
\text { - Rare as the valves in the perforating veins of upper extremities are oriented toward the } \\
\text { superficial veins } \\
\text { - Congenital } \\
\text { - Klippel-Trenaunay syndrome } \\
\text { - Parkes Weber syndrome } \\
\text { - Secondary } \\
\text { - Venous outflow obstruction caused by deep vein thrombosis or arteriovenous fistulae }\end{array}$ \\
\hline Pathophysiology & $\begin{array}{l}\text { - Collagen defects in the vein wall resulting in weakness and dilation is most accepted theory of } \\
\text { upper extremity primary varicose veins, which is alsapplicable for lower extremity varicosities }\end{array}$ \\
\hline Diagnosis & $\begin{array}{l}\text { - Noninvasive investigations } \\
\text { - Color Doppler ultrasound } \\
\text { Invasive tests } \\
\circ \text { Phlebography } \\
\circ \text { Arteriography (when congenital and anatomical variations are suspected) }\end{array}$ \\
\hline Treatment & $\begin{array}{l}\text { - Same as lower limb varicosities } \\
\text { - Ligation and stripping } \\
\text { - Multiple ligation and excision of localized varicose vein segments } \\
\text { - Sclerotherapy } \\
\text { - Surgical division of the fistula (for arteriovenous fistulae) }\end{array}$ \\
\hline
\end{tabular}

\section{Conclusion}

We report the case of primary upper extremity varicose veins due to its rarity of occurrence and limited availability of data in the literature.

\section{Conflicts of Interest}

None declared.

\section{Acknowledgments}

We sincerely thank the organizers of the Sri Sathya Sai Mobile Hospital, Puttaparthi for paving the way to identify such rare entities.

\section{References}

1 Clark DM, Warren R. Idiopathic varicose veins of the upper extremity. N Engl J Med 1954;250(10):408-412

2 Welch HJ, Villavicencio JL. Primary varicose veins of the upper extremity: a report of three cases. J Vasc Surg 1994;20(5):839-843
3 Donogue GO, Leahy A. Varicose veins. Surgery 2002;1:8-11

4 Jain S, Jain P, Singh T, Aggarwal N, Singh A. Primary varicose veins of the upper extremity: a case report. Indian J Surg 2004;66:169-171

5 Browse NL, Burnand KG, Thomas ML. Embryology and radiographic anatomy and physiology and functional anatomy. In: Diseases of the Veins: Pathology, Diagnosis, and Treatment. London: Edward Arnold;1988;23-70

6 Sreekar H, Dawre S, Petkar KS, et al. Diverse manifestations and management options in Klippel-Trenaunay syndrome: a single centre 10-year experience. J Plast Surg Hand Surg 2013;47(4):303-307

7 Girón-Vallejo O, López-Gutiérrez JC, Fernández-Pineda I. Diagnosis and treatment of Parkes Weber syndrome: a review of 10 consecutive patients. Ann Vasc Surg 2013;27(6):820-825

8 Kawakatsu M, Fujiwara M, Iwasaki K, Sumiya A. A case of venous varix of the volar digit and review of the literature. Hand Surg 2009;14(1):53-56

9 Hans S, Singh NP, Dhall K, Khichy S. Varicose veins of the dorsum of hand and digits: A case report and review of literature. Saudi Surg J 2014;2(1 ) :26-28 